\title{
Anti-dumping Laws and Oligopolistic Trade
}

\author{
Jiang Bian \\ University of Singapore \\ Gérard Gaudet \\ Université de M ontréal
}

\begin{abstract}
We study the effect of anti-dumping laws in a differentiated products quanti ty-setting oligopoly. Dumping may or may not occur in the model and may or may not be reciprocal. We show that the effect of adopting an anti-dumping policy on the welfare of the importing country is ambiguous. It can even lead to an increase in the consumers' surplus in the importing country. Hence the importing country may in some cases find strong reasons for the adoption of an anti-dumping policy. We then study the endogenous determination of the equi librium anti-dumping policies in a two-stage game with reciprocal dumping in which the two governments simultaneously choose anti-dumping policies in a first stage. We provide a sufficient condition, relating the degree of substi tutability in demand between the two goods and transport cost, in order for

* Correspondence Address: Gérard Gaudet: Département de sciences économiques, Université de M ontréal, C.P. 6128, Succursale Centre-ville, M ontréal, Q uébec H3C 3J 7, Canada. E-mail: gaudet@crt.umontreal.ca; Tel.: 514-343-7908; Fax: 514-343-7221; Jiang Bian: Department of E conomics and Statistics, University of Singapore, Singapore; We gratefully acknowledge financial support for this research from the Fonds FCAR du Gouvernement du Québec and the Social Science Research Council of Canada. Gaudet benefited from the hospitality of the GREQAM, Universite d'Aix$M$ arseille II, while working on this paper.
\end{abstract}

(C1997 - Institute for International Economics, Sejong Institution. All rights reserved. 
each country to have an incentive to deviate unilaterally from free trade in the presence of anti-dumping laws. We show that governments acting cooperatively to maximize world welfare should choose to endorse the institution of antidumping laws. (JEL Classification: F 12, F13, L13)

\section{Introduction}

The recourse to anti-dumping laws has been a very common source of international trade restriction in recent years. For instance, between 1980 and 1988 a total of 1665 anti-dumping procedures have been initiated, a very high proportion of which have resulted in anti-dumping duties being applied. ${ }^{1}$ Such prevalent use of this restrictive trade policy is at odds with the common belief in the literature on the subject that no normative case can be made for it, or that, at best, it always gives rise to a trade-off between consumer and producer surplus. In this paper we show that there are conditions under which no such trade-off occurs and therefore the use of antidumping duties as an instrument of trade policy is welfare enhancing for the importing country. Furthermore we study the propensity of the governments to actually take advantage, in equilibrium, of the anti-dumping laws, in a context where reciprocal dumping occurs.

A common explanation of dumping in international trade is as a form of monopolistic price discrimination. In the simplest version, a monopolist selling an identical product both at home and abroad charges an international price differential which is less than would be justified by the difference in marginal costs, inclusive of transport costs. It thus discriminates in favor of the importing country. It is well known from the standard theory of price discrimination that prohibiting such behavior by somehow forcing the monopolist to charge a price differential which exactly reflects the difference in marginal costs has an ambiguous effect on total world welfare. What is more, it has a detrimental effect on the welfare of the importing country, since this will increase the price to the consumer in that country. There is

1. See the figures cited by Jackson [1989]. Australia, Canada, the U nited States and the European Economic Community account for over ninety percent of the investigations initiated over that period. 
therefore apparently no normative reason for the importing country to favor such a prohibition. In another version of essentially the same explanation, the firm is a (protected) monopolist in its own country but faces a perfectly competitive price in the importing country. Again there is nothing to gain for the importing country from constraining the firm to a lower price in its own market.

This standard analysis incompletely captures the welfare effects of actual GATT/WTO anti-dumping provisions. Firstly, these provisions do not "prohibit" dumping. Rather, the agreement allows for an anti-dumping duty to be levied by the importing country in cases where dumping can be shown to occur. Thus anti-dumping actions are better viewed as endogenous tariffs on imports than as exogenous constraints on international price differentials. Secondly, the agreement requires that an "injury test" be passed before permitting anti-dumping duties. Since no one in the importing country is "injured" by the dumping in the simple monopoly model described above, one would expect never to observe anti-dumping actions. Clearly, a strict monopoly framework is inappropriate. An appropriate model must meaningfully account for the presence of firms in the importing country producing (or at least potentially producing) a substitute product. The more so since dumping complaints are usually brought about at the initiative of such firms.

Since the existence of some monopoly power is a prerequisite for price discrimination to occur, the analysis of dumping requires some form of imperfect competition. ${ }^{2}$ An interesting example of an oligopoly model of dumping is that of Brander and Krugman [1983]. ${ }^{3}$ They consider a model

2. Some form of imperfect competition is also essential to most other explanations of dumping. These often require that the definition of dumping be broadened to "selling below cost", for predatory or other reasons 〈see Davies and M cGuiness [1982] $\rangle$. However, instances where dumping viewed as selling below cost may occur under perfect competition are provided by Ethier [1982]. His could be termed a model of cyclical dumping, as could the model of Staiger and Wolak [1992], in which competitive domestic firms face a foreign monopolist. Predatory dumping is studied for instance in Fudenberg and Tirole [1986], Eaton and M irman [1991] and Hartigan [1994, 1996]. For a useful critical survey of some of the different approaches to dumping, see Deardorff [1989]. 
where duopolistic firms sell identical products and face a positive transport cost when selling abroad. They show that because of the oligopolistic competition, two-way trade occurs in Cournot equilibrium, with each firm dumping into the other's home market. The fact that the products are perfect substitutes and that the two countries are in every way identical results in the dumping being necessarily reciprocal in this model. ${ }^{4}$ Dixit [1988] introduces differentiated products in a conjectural variations model of international oligopoly. He studies the importing country's optimal response to an increase in the competitive conduct by the foreign firm in the importing country's market. This is done by considering an exogenous change in the corresponding conjectural variation parameter, which leads to an increase in the equilibrium dumping margin. Thus dumping is modeled very imprecisely in this model. More recently, Anderson, Schmitt and Thisse [1995] have also used a differentiated products oligopoly model to study anti-dumping legislation, although with price competition. They analyze the incentive to introduce rules forbidding price discrimination in the presence of transport costs. They treat the anti-dumping legislation as a means of enforcing "tied markets", wherein firms are subject to the f.o.b. pricing constraint that their export price be equal to their home price plus the transport cost (or, more generally, the trade barrier, which may include a tariff). They thus interpret the anti-dumping legislation as prohibiting dumping and do not study the effect of anti-dumping duties as such. ${ }^{5}$

The model employed in this paper to study dumping and the effect of antidumping laws is essentially the Cournot competition version of the Dixit

3. Pinto [1986], Webb [1992] and Reitze [1993] and Hartigan [1995] also rely on some form of homogeneous good oligopoly framework, the last one with incomplete cost information. The model of Pinto is a repeated game version of that of Brander and Krugman.

4. Weinstein [1992] introduces arbitrary numbers of firms in the same model and shows that if there is sufficient asymmetry in the number of firms between the two countries, the equilibrium will be characterized by one-way trade and unilateral dumping. Interestingly, the firms doing the dumping will be those in the market with the larger number of domestic competitors.

5. Other recent contributions to the analysis of various aspects of anti-dumping policies include Anderson [1992, 1993], Staiger and Wolak [1991], Prussa [1992, 1994], Webb [1992], Reitzes [1993], M oore and Suranovic [1994] and Hartigan [1994, 1995, 1996]. 
model. Thus unlike in the Brander and Krugman model, the countries produce differentiated products. As we will show, dumping may or may not occur in this model and may or may not be reciprocal, depending on the form of the demand functions for each product.

We will show that the effect of imposing an anti-dumping duty on the welfare of the importing country also depends on the demand functions. In fact, in some cases it can even lead to an increase in the consumers' surplus in the importing country. Hence the importing country may in some cases find strong and unambiguous normative reasons for the imposition of an anti-dumping duty, even though this is possibly detrimental to world welfare. ${ }^{6}$ Anti-dumping duties may thus appear to the importing country as a more attractive instrument of trade policy than the simple monopoly model of price discrimination would predict.

In order to study the endogenous determination of the equilibrium antidumping duties, we consider a two-stage game with reciprocal dumping in which the two governments simultaneously choose anti-dumping policies in a first stage taking into account that the firms will in a second stage simultaneously compete in quantities given those policies. For the case where both demands are linear, a situation in which reciprocal dumping occurs, we show that each firm stands to gain if its government resorts to an antidumping policy. We provide a sufficient condition, relating the degree of substitutability in demand of the two goods to transport costs, in order for each social welfare maximizing government to have an incentive to unilaterally deviate from free trade by adopting an anti-dumping policy which calls for an endogenously determined positive anti-dumping duty when dumping occurs. Thus if free trade were observed to remain an equilibrium in the presence of the international anti-dumping provisions, then it must be the case that this condition is violated. We also show that if the governments were to act cooperatively in order to maximize world welfare, they would want to deviate from free trade through the use of anti-dumping policies and therefore would be likely to sanction the adoption of anti-dumping provi-

6. This is unlike Dixit [1988], where no normative case for anti-dumping duties is found. Anderson, Schmitt and Thisse [1992], on the other hand, find that unilateral imposition of tied markets increases a country's social surplus when transport costs constitute the only trade barrier. 
sions as part of an inter national agreement.

In the next section, we present the model that will be employed and derive conditions under which dumping will occur. We then go on in the following section to take into account the existence of anti-dumping laws into the model. This is done by introducing the anti-dumping duty in the form of an endogenous tariff, which can take a positive value only when the country has adopted an anti-dumping policy calling for an anti-dumping duty to be applied when dumping by the foreign firms occurs. We are then in a position to study, in the two sections that follow, the effect on output and trade, and especially on the welfare of the importing country, of actually applying the tariff in question. The last section before the conclusion considers the endogenous determination of the anti-dumping policies in the two-stage game just mentioned.

\section{The Model}

The model is one of trade between two countries whose firms compete in quantities sold and whose two products are differentiated. The two countries are assumed otherwise identical. They each have the same number of identical firms - which we assume equal to one for simplicity - and their consumers have identical preferences. For ease of exposition we will speak of the two countries as the "home" country and the "foreign" country. Each firm treats the two markets as segmented.

Denote the domestic sales of the home good by $x$ and its export to the foreign country by $X$. Denote by $Y$ the domestic sales of the foreign firm and by $y$ its export to the home country. The utility of the home and foreign consumers are assumed given respectively by $Z+U(X, y)$ and $Z+U(X, Y)$, where $z$ and $Z$ represent the quantity of some competitively supplied numéraire. From these we derive the inverse demand functions

$$
P_{x}(x, y)=\partial U(x, y) / \partial x, \quad P_{y}(x, y)=\partial U(x, y) / \partial y
$$

and

$$
P_{X}(X, Y)=\partial U(X, Y) / \partial X, \quad P_{y}(X, Y)=\partial U(X, Y) / \partial Y .
$$

They are assumed to have continuous negative first derivatives with respect 
to both arguments. Thus the demand curves are downward sloping and the two goods are substitute in demand.

The two firms have constant and identical marginal costs of production, denoted $c$. Furthermore, each faces a positive transport cost of $t$ per unit of the good sold to the other country. Under free trade, the home firm's profit function is therefore

$$
\pi=P_{X}(X, y) X-c X+P_{X}(X, Y) X-(c+t) X
$$

which it maximizes with respect to $x$ and $X$ taking $y$ and $Y$ as given. Similarly, the foreign firm's profit function is

$$
\Pi=P_{y}(x, y) y-(c+t) y+P_{y}(X, Y) Y-c Y
$$

which it maximizes with respect to $y$ and $Y$ taking $x$ and $X$ as given. Dumping occurs when the price at which a firm sells its good to consumers in its own country exceeds the price net of transport cost at which it sells it to consumers in the other country.

Let $\left(X^{0}, y^{0}, X^{0}, Y^{0}\right)$ denote a free-trade Cournot equilibrium. It must satisfy the following first-order conditions:

$$
\begin{aligned}
& P_{x}\left(x^{0}, y^{0}\right)+x^{0} \frac{P_{x}\left(x^{0}, y^{0}\right)}{x}-c=0 \\
& P_{x}\left(X^{\circ}, Y^{0}\right)+X^{\circ} \frac{P_{x}\left(X^{0}, Y^{0}\right)}{X}-c-t=0 \\
& P_{y}\left(X^{0}, y^{0}\right)+y^{0} \frac{P_{y}\left(x^{0}, y^{0}\right)}{y}-c-t=0 \\
& P_{y}\left(X^{0}, Y^{0}\right)+Y^{\circ} \frac{P_{y}\left(X^{0}, Y^{0}\right)}{Y}-c=0
\end{aligned}
$$

We will assume

$$
\frac{P_{x}(u, v)}{v}+u \frac{{ }^{2} P_{x}(u, v)}{u v}<0 \text { and } \frac{P_{y}(u, v)}{u}+v \frac{{ }^{2} P_{y}(u, v)}{v u}<0
$$

as well as 


$$
2 \frac{P_{x}(u, v)}{u}+u \frac{{ }^{2} P_{x}(u, v)}{u^{2}}<0 \text { and } 2 \frac{P_{y}(u, v)}{v}+v \frac{{ }^{2} P_{y}(u, v)}{v^{2}}<0
$$

where $\{u, v\}=\{x, y\}$ or $\{X, Y\}$. Assumptions (7) mean that marginal revenue is a decreasing function of the other firm's output, for both goods in both markets. The strict concavity assumptions (8) guarantee that the second order conditions hold and that $\left(X^{0}, y^{0}, X^{0}, Y^{\circ}\right)$ is indeed a Cournot equilibrium.

Denote the reaction functions obtained from (3) to (6) by $x=r(y), X=$ $\tilde{r}(Y), y=R(X)$ and $Y=\tilde{R}(X)$ respectively. From assumptions (7) and (8), we know that $r^{\prime}(y)<0, \tilde{r}^{\prime}(Y)<0, R^{\prime}(x)<0$ and $\tilde{R}^{\prime}(X)<0$, i.e., the goods are strategic substitutes. It also follows from the same assumptions that with $t>0, x^{0}>X^{0}$ and $y^{0}<Y^{0}$. We will further assume that $R^{\prime}\left(X^{0}\right) r^{1}\left(y^{0}\right)<1$ and $\tilde{R}^{\prime}\left(X^{0}\right) \tilde{r}^{\prime}\left(Y^{0}\right)<1$. This guarantees that $\left(X^{0}, Y^{0}, X^{0}, Y^{0}\right)$ is unique and stable.

Now let $\varepsilon_{x}(\cdot)$ and $\varepsilon_{y}(\cdot)$ denote the elasticities of demand for the product of the home country and that of the foreign country respectively. Then, from (3) and (4), dumping of the home product will occur if and only if

$$
\frac{x^{(}\left(X^{0}, Y^{0}\right)-x_{x}\left(x^{0}, y^{0}\right)}{x^{0}\left(x^{0}, y^{0}\right)-1}>\frac{t}{c}
$$

A necessary though not sufficient condition for this is that the elasticity of demand of the home product be greater in the foreign country than in the home country, i.e., $\varepsilon_{x}(X, Y)>\varepsilon_{x}(X, y)$. It can be shown (see the appendix) that the following restrictions on the demand function of the home product are sufficient for dumping of the home product to occur:

$$
\frac{{ }^{2} P_{x}(u, v)}{u^{2}} \leq 0 \text { and } \frac{{ }^{2} P_{x}(u, v)}{u v} \geq 0
$$

Similarly, from (5) and (6), dumping of the foreign product will occur if and only if

7. Whenever $t=0$ in this model, we have $x^{0}=X^{0}, y^{0}=Y^{0}, P_{X}\left(x^{0}, y^{0}\right)=P_{X}\left(X^{0}, Y^{0}\right)$ and $P_{y}\left(x^{0}, y^{0}\right)$ $=P_{y}\left(X^{0}, Y^{0}\right)$. Thus international trade persists, although there is no price discrimination and hence no dumping. This is a property shared with the Brander and Krugman model. 


$$
\frac{{ }_{y}\left(X^{0}, y^{0}\right)-{ }_{y}\left(X^{0}, Y^{0}\right)}{{ }_{y}\left(X^{0}, Y^{0}\right)-1}>\frac{t}{C}
$$

a necessary condition being that the elasticity of demand for the foreign product be greater in the home country than in the foreign country, i.e., $\varepsilon_{y}(X, y)>\varepsilon_{y}(X, Y)$. Again, it is sufficient for dumping of the foreign product to occur that the following restrictions be imposed on the demand for the foreign product (see the appendix):

$$
\frac{{ }^{2} \mathrm{P}_{\mathrm{y}}(\mathrm{u}, \mathrm{v})}{\mathrm{u}^{2}} \leq 0 \text { and } \frac{{ }^{2} \mathrm{P}_{\mathrm{y}}(\mathrm{u}, \mathrm{v})}{\mathrm{u} v} \geq 0
$$

Reciprocal dumping will occur if and only if conditions (9) and (11) hold simultaneously.

Which situation will be observed in equilibrium clearly depends on the form of the demand functions. As examples, it is easy to verify that dumping of a product will necessarily occur if its demand function is linear but will never occur if its demand function is of constant elasticity. ${ }^{8}$ Hence, if both demand functions were linear, reciprocal dumping would occur. However, if one of the demand functions were linear and the other of constant elasticity, one-way dumping would occur.

We will assume in the next three sections that one-way dumping takes place in the free trade equilibrium, with the foreign product being dumped into the home market. In section 6 we will study the equilibrium anti-dump-

8. This is because if the demand for, say, the product of the home country is isoelastic, then necessarily $\varepsilon_{X}\left(X^{0}, Y^{0}\right)=\varepsilon_{X}\left(X^{0}, y^{0}\right)$ and therefore (9) cannot be satisfied. Notice however that in the limiting case where the two goods are perfect substitutes, if $\eta(\cdot)$ is the elasticity of the total demand in each country, then the perceived demand elasticities of the home firm are $\varepsilon_{X}(X, Y)=(X+Y) \eta(X+Y) / X$ on the foreign market and $\varepsilon_{\mathrm{x}}(\mathrm{X}, \mathrm{y})=(\mathrm{x}+\mathrm{y}) \eta(\mathrm{x}+\mathrm{y}) / \mathrm{x}$ on the domestic market. It follows that when the products are perfect substitutes, $\varepsilon_{x}(\cdot)$ is not constant when $\eta(\cdot)$ is constant, since a firm's perceived demand elasticity in a market then depends on its share of that market. Although by symmetry $x^{0}+y^{0}=X^{0}+Y^{0}$, we have $x^{0}>X^{0}$ when $t$ is positive. The lefthand side of ( 9 ) is therefore positive when $\eta(\cdot)$ is constant, as is the case for (11), which is then identical to (9). This explains why Brander and Krugman [1983] find that reciprocal dumping occurs in their constant elasticity example if $t$ is not too large: they assume perfect substitutes and are therefore referring to the elasticity of the total demand. 
ing duties in a situation where reciprocal dumping occurs.

\section{Anti-dumping Laws}

The last section assumed free trade. N ow consider the situation where an international anti-dumping agreement exists that allows for each country to adopt an anti-dumping policy, providing for the levy of a duty when dumping occurs in its market.

When considering dumping of the foreign product into the home market, the "dumping margin" is

$$
M(x, y, X, Y) \equiv P_{y}(X, Y)+t-P_{y}(X, y) \text {. }
$$

Dumping is said to occur whenever $M(X, Y, X, Y)$ is positive. The GATT/ WTO provisions allow a country to apply an anti-dumping duty in order to offset part or all of the dumping margin provided dumping can be shown to occur. The foreign firm's profit may therefore now be written

$$
\Pi=P_{y}(x, y) y-(c+t) y+P_{y}(X, Y) Y-c Y-\tau y
$$

where

$$
\tau=\max \{0, k M(X, y, X, Y)\}
$$

and $k$ is a parameter to be determined by the home government subject to $k \in[0,1]$. Thus choosing $k=0$ may be thought of as choosing not to adopt an anti-dumping policy. Choosing $k>0$ means that the policy consists in applying an anti-dumping duty equal to $k$ times the dumping margin when dumping occurs. What will be the actual value of $\tau$ - the duty itself - is only known once dumping and the dumping margin are observed. Thus the antidumping policy consists in deciding ex ante not the actual duty, but what form the duty will take should dumping occur.

There are two reasons for which one may presume that the home firm stands to gain from the existence of an anti-dumping policy. The first is that activation of the anti-dumping procedures takes place only after a complaint has been initiated by the injured firms. The second is that in order for the home country to be permitted to utilize the anti-dumping duty, it must be shown, in addition to its existence, that the dumping causes "material 
injury" to the competing home industry. We will try to capture this by assuming that $\mathrm{k}$ will be greater than zero only if in the restricted trade equilibrium it can be verified that ${ }^{9}$

$$
\left.\frac{\mathrm{d}}{\mathrm{dk}}\right|_{\mathrm{k}=0}>0 \text {. }
$$

We show in the appendix that if dumping by the foreign firm takes place in the free trade equilibrium, then the Cournot equilibrium under restricted trade must solve the simultaneous maximization of (1) and of (13) where $\tau$ has been replaced by $\tau=k M(X, y, X, Y)$. Conditions (5) and (6) must therefore be replaced by

$$
\begin{aligned}
& (1+k)\left[P_{y}(x, y)+y \frac{P_{y}(x, y)}{y}-t\right]-k P_{y}(X, Y)-c=0 \\
& P_{y}(X, Y)+[Y-k y] \frac{P_{y}(X, Y)}{Y}-c=0,
\end{aligned}
$$

while (3) and (4) remain unchanged.

Solving (15) and (16) simultaneously for $y$ and $Y$ given $x$ and $X$, gives the reaction functions $(y, Y)=(\mathcal{R}(x, X ; k), \widetilde{R}(x, X ; k))$ of the foreign firm, which satisfy $\mathcal{R}(x, X ; 0)=R(x)$ and $\widetilde{R}(x, X ; 0)=\widetilde{R}(X)$. By Cramer's rule,

$$
\frac{R(x, X ; k)}{x}=-\frac{(1+k)\left\lfloor\frac{P_{y}}{x}+y \frac{{ }^{2} P_{y}}{y x}\right\rfloor\left\lfloor 2 \frac{P_{y}}{Y}+(Y-k y) \frac{{ }^{2} P_{y}}{Y^{2}}\right\rfloor}{\Delta}
$$

and

$$
\frac{\tilde{R}(x, X ; k)}{X}=-\frac{(1+k)\left\lfloor 2 \frac{P_{y}}{y}+y \frac{{ }^{2} P_{y}}{y^{2}}\right\rfloor\left\lfloor\frac{P_{y}}{X}+(Y-k y) \frac{{ }^{2} P_{y}}{X Y}\right\rfloor+k^{2} \frac{P_{y}}{Y} \frac{P_{y}}{X}}{\Delta}
$$

where

$$
\Delta=(1+k)\left[2 \frac{P_{y}}{y}+y \frac{{ }^{2} P_{y}}{y^{2}}\right]\left[2 \frac{P_{y}}{Y}+(Y-k y) \frac{{ }^{2} P_{y}}{Y^{2}}\right]-k^{2}\left(\frac{P_{y}}{Y}\right)^{2} .
$$

9. In reality, this local condition is not necessary for the home firm to gain from an application of the anti-dumping duty, since it cannot be ruled out that a non-marginal application of the duty might increase its profits even though (14) did not hold. It is however sufficient. 
By assumptions (7) and the second-order conditions, $\partial \mathcal{R}(\mathrm{x}, \mathrm{X} ; \mathrm{k}) / \partial \mathrm{x}<0$. However $\partial \widetilde{\mathcal{R}}(\mathrm{X}, \mathrm{X} ; \mathrm{k}) / \partial \mathrm{X}$ is of indeterminate sign, although $\partial \widetilde{\mathcal{R}}(\mathrm{X}, \mathrm{X} ; 0) / \partial \mathrm{X}<0 .{ }^{10}$

\section{The Effects on Outputs and Prices}

Now consider the effect of introducing the anti-dumping policy on the domestic sales and export sales of the foreign firm.

The four first-order conditions (3), (4), (15) and (16) can be reduced to a system of two equations in $y$ and $Y$ by replacing $x$ and $X$ in conditions (15) and (16) by the best responses of the home firm to any $y$ and $Y$, namely $r(y)$ and $\widetilde{r}(Y)$. Differentiating totally, we then find

$$
\left.\frac{d y}{d k}\right|_{k=0}=\frac{-Y \frac{P_{y}(\tilde{r}(Y), Y)}{Y}}{\left[1-\frac{R(r(y), \tilde{r}(Y) ; 0)}{x} r^{\prime}(y)\right]\left[2 \frac{P_{y}(r(y), y)}{y}+y \frac{{ }^{2} P_{y}(r(y), y)}{y^{2}}\right]}
$$

and

$$
\left.\frac{d Y}{d k}\right|_{k=0}=\frac{-y \frac{P_{y}(\tilde{r}(Y), Y)}{Y}}{\left[1-\frac{\tilde{R}(r(y), \tilde{r}(Y) ; 0)}{X} \tilde{r}^{\prime}(Y)\right]\left[2 \frac{P_{y}(\tilde{r}(Y), Y)}{Y}+Y \frac{{ }^{2} P_{y}(\tilde{r}(Y), Y)}{Y^{2}}\right]}
$$

Note that $\partial \mathcal{R}(r(y), \tilde{r}(Y) ; 0) / \partial X=R^{\prime}(r(y))$ and $\partial \tilde{R}(r(y), \tilde{r}(Y) ; 0) / \partial X=\tilde{R}^{\top}(\tilde{r}(Y))$. It follows from the stability conditions and the concavity assumptions (8) that

$$
\left.\frac{\mathrm{dy}}{\mathrm{dk}}\right|_{\mathrm{k}=0}<0 \text { and }\left.\frac{\mathrm{dY}}{\mathrm{dk}}\right|_{\mathrm{k}=0}>0,
$$

and hence

$$
\left.\frac{\mathrm{dx}}{\mathrm{dk}}\right|_{\mathrm{k}=0}=\left.\mathrm{r}^{\prime}(\mathrm{y}) \frac{\mathrm{dy}}{\mathrm{dk}}\right|_{\mathrm{k}=0}>0 \text { and }\left.\frac{\mathrm{dX}}{\mathrm{dk}}\right|_{\mathrm{k}=0}=\left.\tilde{r}^{\prime}(\mathrm{Y}) \frac{\mathrm{d} \mathrm{Y}}{\mathrm{dk}}\right|_{\mathrm{k}=0}<0 \text {. }
$$

Thus, at least in a neighborhood of the free trade equilibrium, the introduction of the anti-dumping policy unambiguously reduces international

10. We can also verify that $\partial \widetilde{\mathcal{R}}(\mathrm{x}, \mathrm{X} ; \mathrm{k}) / \partial \mathrm{x}<(=) 0$ for $\mathrm{k}>(=) 0$ and that $\partial \mathcal{R}(\mathrm{x}, \mathrm{X} ; \mathrm{k}) / \partial \mathrm{X}$ is of indeterminate sign although $\partial \mathcal{R}(\mathrm{x}, \mathrm{X} ; 0) / \partial \mathrm{X}=0$. 
trade. The effect on the total output of each good is however ambiguous. This is the case also of the effect on prices: in each market, to the effect of the change in the quantity of the good on its own price must always be added an opposite effect due to the change in the quantity of its substitute.

However, at least in the case where the sufficient conditions (12) for dumping hold, ${ }^{11}$ it can be shown that there exists no $k \in[0,1]$ such that the dumping margin would be reduced to zero in the new equilibrium. Thus if dumping of the foreign product occurred in the free trade equilibrium, it will persist in the presence of the anti-dumping laws.

To show this, suppose that $P_{y}(X, Y)+t-P_{y}(X, y)=0$ for some $k \in[0,1]$ in the restricted trade equilibrium. It would then follow from the first-order conditions (15) and (16) that

$$
(y-k y) \frac{P_{y}(x, y)}{y}=(Y-k y) \frac{P_{y}(X, Y)}{Y} .
$$

But since in equilibrium $y<Y$ and $x>X$, this is not possible if (12) holds.

\section{The Effects on Welfare}

The next question concerns the effects of the anti-dumping policy on welfare. N ot surprisingly, since we are already dealing with a second best situation in the free trade equilibrium, the overall welfare effect will be ambiguous. It is interesting however to have a closer look at the effects on the welfare of the home country, since this can potentially motivate the use of antidumping duties as an instrument of trade policy.

The welfare of the home country is given by

$$
w=s+\pi+g
$$

where

$$
S=U(x, y)-P_{x}(x, y) x-P_{y}(x, y) y
$$

is the consumers surplus, $\pi$ is the profit of the home firm, given by (1), and

$$
g=k\left[P_{y}(X, Y)+t-P_{y}(X, y)\right] y
$$

11. For instance if $P_{y}(\cdot)$ is linear. 
is the government tariff revenue.

Clearly, the government stands to gain from a marginal application of the tariff, in the sense that

$$
\left.\frac{\mathrm{dg}}{\mathrm{dk}}\right|_{\mathrm{k}=0}=\left[\mathrm{P}_{\mathrm{y}}(X, Y)+\mathrm{t}-\mathrm{P}_{\mathrm{y}}(\mathrm{X}, \mathrm{y})\right] \mathrm{y}>0
$$

As for the effect on profit, it is given by

$$
\left.\frac{d}{d k}\right|_{k=0}=\left.x \frac{P_{x}(x, y)}{y} \frac{d y}{d k}\right|_{k=0}+\left.X \frac{P_{x}(X, Y)}{Y} \frac{d Y}{d k}\right|_{k=0}
$$

which we have already assumed positive as a precondition for the antidumping procedure to be initiated. There remains the effect on the consumers' surplus, which is given by

$$
\left.\frac{d s}{d k}\right|_{k=0}=-\left.\left\{\left[\frac{P_{x}(x, y)}{x} x+\frac{P_{y}(x, y)}{x} y\right] r^{\prime}(y)+\left[\frac{P_{x}(x, y)}{y} x+\frac{P_{y}(x, y)}{y} y\right]\right\} \frac{d y}{d k}\right|_{k=0} \text {. }
$$

The sign of this expression is generally ambiguous. The first term reflects the gains to the consumer coming from the effect on the two prices of the increase in $x$ subsequent to the decrease in $y$. The second term reflects the losses to the consumer coming from the effect of the decrease in $y$ on the two prices. A necessary and sufficient condition for the expression to be positive, and hence for the consumers of the home country to gain is

$$
r^{\prime}(y)<\frac{x \frac{P_{x}(x, y)}{y}+y \frac{P_{y}(x, y)}{y}}{x \frac{P_{x}(x, y)}{x}+y \frac{P_{y}(x, y)}{x}} .
$$

The left-hand side of (27) is the slope of the reaction function. ${ }^{12}$ The righthand side captures the effect on the value of the consumption vector of the change in the two prices resulting from a change in $y$, relative to that of the change in the same two prices resulting from a change in $x$. Thus if the home firm is sufficiently responsive to the reduction in the imports of its substitute product, the gains to the consumer coming from the effect on the

12. Recall that, following the implementation of the anti-dumping policy, the home firm responds to the decrease in the quantity imported from the foreign firm on the home market by increasing its own domestic sales. 
two prices of the increase in $x$ will outweigh the loss coming from the effect on the same two prices of the fall in $y$.

Given the cost structure, the required increase in $x$ by the home firm in response to the reduction in y by the foreign firm in order for (27) to hold depends strictly on the characteristics of the demand functions. One such important characteristic will be the degree of substitutability in demand of the two goods. For instance, ceteris paribus, the lower the degree of substitutability of $y$ for $x$ (the smaller the absolute value of $\partial P_{x}(x, y) / \partial y$ ), the smaller the upward pressure on the price of the home product from the decreased competition from the foreign product. As a result, the smaller the required upward response in the home firm's domestic sales in order for the gains to the consumer from the downward pressure on the two prices to outweigh the loss from the upward pressure. Hence the more likely the consumer is to gain.

Condition (27) is sufficient (though not necessary) for the welfare of the home country to increase as a result of the implementation of the antidumping policy. Whenever it is satisfied, the optimal anti-dumping duty from the home country's point of view is positive without ambiguity assuming it is also beneficial to the home firm. Thus one would expect the home government to look all the more favorably upon an anti-dumping procedure initiated by the home firm. ${ }^{13}$

The world welfare as well as the welfare of the foreign country remain indeterminate even if (27) is satisfied. It is interesting to note that, theoretically at least, even the foreign firm may benefit from the introduction of the anti-dumping duty. The effect on the foreign firm's profit is given by

$$
\left.\frac{d \Pi}{k}\right|_{k=0}=\left.y \frac{P_{y}(x, y)}{x} \frac{d x}{d k}\right|_{k=0}+\left.Y \frac{P_{y}(X, Y)}{X} \frac{d X}{d k}\right|_{k=0}-\left[P_{y}(X, Y)+t-P_{y}(x, y)\right] y .
$$

Its sign clearly depends on the form of the demand function for its product. The effect on the consumers surplus in the foreign country is also ambiguous.

13. As correctly pointed out by an anonymous referee, it should be noted however that in reality the interest of the producers remains paramount in many countries. Indeed, the major users of the GATT/WTO anti-dumping provisions (Australia, Canada, European Community, United States) have no national interest clause as part of their anti-dumping laws. 


\section{Equilibrium Resort to Anti-dumping Policies}

In the previous sections we assumed that dumping was strictly one-way and considered the incentives for the importing country to apply an antidumping duty. It is now appropriate to ask whether the model can predict what use will actually be made of the anti-dumping provisions when firms in both countries have an interest to dump and actually do so in free trade equilibrium.

To study this question, we assume that both demand functions are linear. As shown in section II, reciprocal dumping will then occur. M ore specifically, we will assume that the demands are symmetric and given by ${ }^{14}$

$$
P_{x}(u, v)=1-a u-b v, \quad P_{y}(u, v)=1-a v-b u
$$

where $\{u, v\}=\{x, y\}$ or $\{X, Y\}$ and $a$ and $b$ are positive constants.

We now introduce another stage to the game, during which the two governments simultaneously set the parameters $k$, for the home government, and its equivalent $K$, for the foreign government. As in the last three sections, those parameters determine the anti-dumping duties as a percentage of the dumping margins. They are constrained by the anti-dumping provisions to the interval $[0,1]$. Thus in a first stage, each government simultaneously chooses its policy parameter in order to maximize the country's social welfare, given that in a second stage the firms will be competing in quantities using the parameters chosen in the first stage. In the second stage the firms simultaneously determine their productions for both markets in order to maximize their total profit, taking as given the set of anti-dumping policies resulting from the first stage.

Given the demands specified in (29), the set of first-order conditions which determines the second-stage production levels, $x, X, y, Y$, as a function of $k$ and $K$ are

$$
\begin{aligned}
& 1-2 a x-b y+a K X-c=0 \\
& 1+a K x+b K y-2 a(1+K) X-b(1+K) Y-(1+K) t-c=0
\end{aligned}
$$

14. These demand functions follow from a quadratic utility function of the form $U(u, v)=$ $u+v-a u^{2} / 2-a v^{2} / 2-b u v$. 


$$
\begin{aligned}
& 1+a k y-b X-2 a Y-c=0 \\
& 1-b(1+k) x-2 a(1+k) y+b k X+a k Y-(1+k) t-c=0 .
\end{aligned}
$$

Assuming $2 a-b>2 a t /(1-c) \geq 0$ guarantees that trade occurs at the free trade equilibrium. It also guarantees the nonsingularity of the matrix of this linear system of equations. It is then a fairly simple matter to solve this set of conditions for the production levels $\mathrm{X}, \mathrm{X}, \mathrm{y}$ and $\mathrm{Y}$ as a function of $\mathrm{k}$ and $\mathrm{K}$. This solution is provided in the Appendix.

Differentiating the solution with respect to $k$, we find that

$$
\begin{aligned}
& \left.\frac{x}{k}\right|_{\substack{k=0 \\
k=0}}=\frac{a b[(1-c)(2 a-b)+b t]}{\left(4 a^{2}-b^{2}\right)^{2}}=\frac{a b x^{0}}{4 a^{2}-b^{2}}>0 \\
& \left.\frac{x}{k}\right|_{\substack{k=0 \\
k=0}}=\frac{-a b[(1-c)(2 a-b)-2 a t]}{\left(4 a^{2}-b^{2}\right)^{2}}=\frac{-a b X^{0}}{4 a^{2}-b^{2}}<0 \\
& \left.\frac{y}{k}\right|_{\substack{k=0 \\
k=0}}=\frac{-2 a^{2}[(1-c)(2 a-b)+b t]}{\left(4 a^{2}-b^{2}\right)^{2}}=\frac{-2 a^{2} Y^{0}}{4 a^{2}-b^{2}}<0
\end{aligned}
$$

and

$$
\left.\frac{Y}{k}\right|_{\substack{k=0 \\ k=0}}=\frac{2 a^{2}[(1-c)(2 a-b)-2 a t]}{\left(4 a^{2}-b^{2}\right)^{2}}=\frac{2 a^{2} y^{0}}{4 a^{2}-b^{2}}>0,
$$

where $\mathrm{X}^{0}, \mathrm{X}^{0}, \mathrm{y}^{0}, \mathrm{Y}^{0}$ are the free trade equilibrium production levels. Hence a marginal deviation from free trade by the home government reduces international trade. Adding (34) and (35) as well as (36) and (37) we find that it unambiguously increases aggregate home production and decreases aggregate foreign production. The reciprocal is true for a marginal deviation from free trade by the foreign government.

Substituting into the profit functions, we also verify that

$$
\left.\frac{\mathrm{d}}{\mathrm{dk}}\right|_{\substack{k=0 \\ \mathrm{~K}=0}}=\left.\frac{\mathrm{d} \Pi}{\mathrm{dK}}\right|_{\substack{\mathrm{k}=0 \\ \mathrm{~K}=0}}>0
$$

Therefore both the home and the domestic firms can gain from a deviation from free trade via the anti-dumping duty by their respective government. They therefore both have an incentive to initiate the complaints necessary for the anti-dumping measures to be applied. 
Substituting the solution of (30) to (33) into the welfare functions of the two governments, one can now, theoretically at least, solve for Nash-equilibrium values of $k$ and $K$. The welfare functions turn out to be highly nonconcave in $\mathrm{k}$ and $\mathrm{K}$, so that it is impossible to get closed form solutions to the subgame perfect equilibrium values of $\mathrm{K}$ and $\mathrm{K}$. We can however still deal with an extremely relevant question, which is under what conditions will, in equilibrium, the governments choose to exploit the anti-dumping provisions by adopting anti-dumping policies. Or, put another way, can free trade, i.e., $\mathrm{k}=\mathrm{K}=0$, remain an equilibrium in the presence of the anti-dumping provisions.

Given the symmetric situations of the two governments, it will suffice to consider the incentives of the home government. Thus consider the impact on the welfare of the home country of a marginal application of an antidumping duty in a neighborhood of free trade. Using the solution of equations (30) to (33) in order to write welfare as a function of $k$ and $K$, we find that

$$
\left.\frac{w}{k}\right|_{\substack{k=0 \\ k=0}}=\frac{-a\left(t-t_{1}\right)\left(t-t_{2}\right)}{\left(4 a^{2}-b^{2}\right)^{2}}
$$

where, letting $\sigma=a / b$,

$$
\mathrm{t}_{1}=\frac{(1+)(6-1)+\sqrt{(1+)\left(4^{4}+16^{3}+9^{2}--1\right)}}{16^{4}+12^{3}-4^{2}-}(2-1)(1-c)>\frac{2-1}{2}(1-c)
$$

and

$$
\mathrm{t}_{2}=\frac{(1+)(6-1)-\sqrt{(1+)\left(4^{4}+16^{3}+9^{2}--1\right)}}{16^{4}+12^{3}-4^{2}-}(2-1)(1-c)<\frac{2-1}{2}(1-c) .
$$

Notice that since we are assuming $2 a-b>2 a t /(1-c) \Rightarrow t<(2 \sigma-1)(1-c) / 2 \sigma$, which is necessary in order for trade to take place, we must have $t-t_{1}<0$. It follows that

$$
\left.\frac{\mathrm{w}}{\mathrm{k}}\right|_{\substack{k=0 \\ \mathrm{k}=0}}>0 \text { if } \mathrm{t}_{2}<\mathrm{t}<(2-1)(1-\mathrm{c}) / 2
$$

and in that case each government has an incentive to unilaterally deviate from free trade by applying an anti-dumping duty. Therefore a necessary though not sufficient condition for free trade to remain an equilibrium is 
Figure 1

\section{Conditions for Free Trade Equilibria}

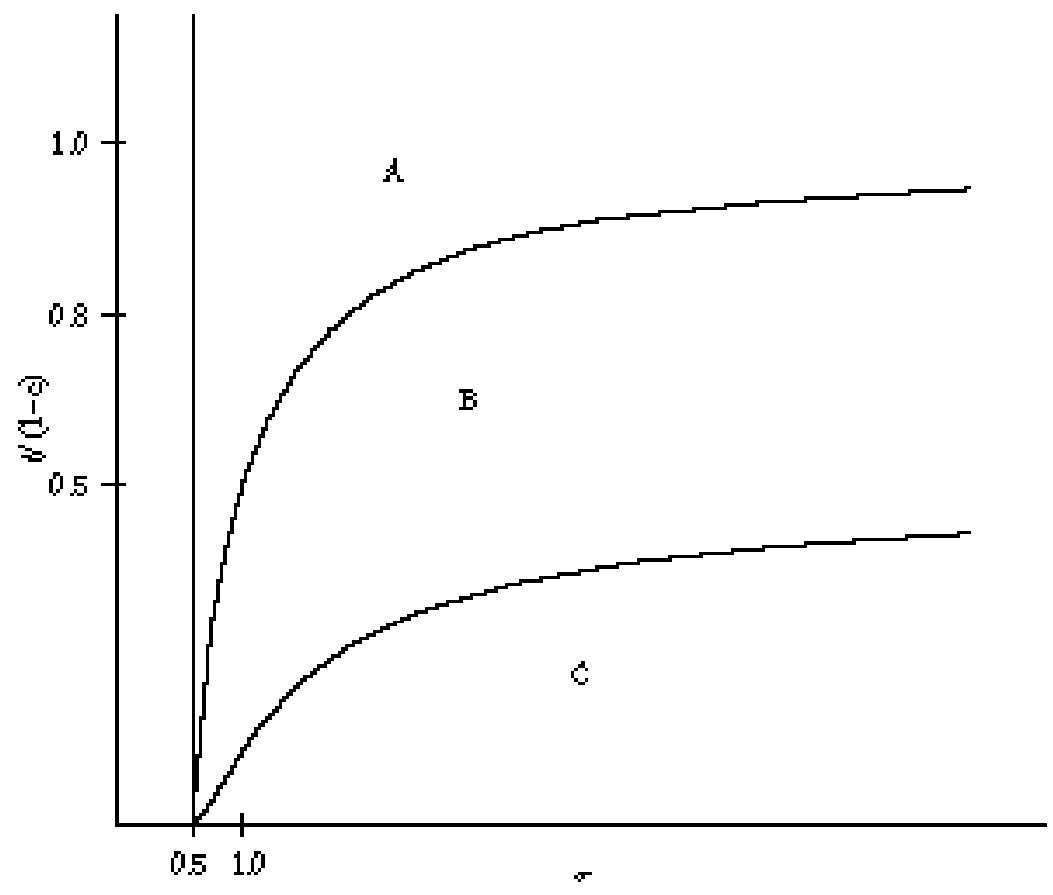

that $\mathrm{t} \leq \mathrm{t}_{2} \cdot{ }^{15}$

This is depicted in Figure 1, with $\sigma$ on the horizontal axis and $t /(1-c)$ on the vertical axis. The curve dividing areas $A$ and $B$ is given by $t /(1-C)=$ $(2 \sigma-1) / 2 \sigma$. It tends to 1 as $\sigma$ goes to infinity. That dividing areas $B$ and $C$ is given by $t /(1-c)=t_{2} /(1-c)$. It tends to $1 / 2$ when $\sigma$ goes to infinity. The parameter $\sigma$ can be viewed as a measure of the degree with which the goods are substitutes in demand. Thus in area A, given a degree of substitutability of the goods, transport cost is prohibitive and no trade occurs. In area $B$, transport cost and the degree of substitutability of the goods are such that free trade cannot be an equilibrium. If free trade is an equilibrium, it must therefore be the case that we are in area $\mathrm{C}$. It is therefore sufficient that the transport cost and the degree of substitutability of the goods be such that we are in area B in order for both governments to resort to anti-

15. The condition is not sufficient since, although there may be no incentive to deviate marginally, a nonmarginal deviation may still increase welfare. Note that if a free trade equilibrium exists, it is not necessarily unique. 
dumping duties in equilibrium.

T wo limiting cases are of particular interest. If $b=a$, so that $\sigma=1$, then the goods are perfect substitutes. In that case ${ }^{16}$ a deviation from free trade will necessarily occur in equilibrium whenever $(1-c)(10-3 \sqrt{6}) / 23<t<(1-c) / 2$. Here the firms gain from the reduced competition and increased price. If the transport cost is relatively high and hence trade small, the government will gain little in revenue, the consumers will lose little of their surplus, and the overall effect on welfare of a unilateral deviation from free trade will be positive. On the other hand, if $b=0$, in which case the goods are independent in demand, then o goes to infinity and we have a double monopoly. In that case, both governments have an incentive to unilateraly deviate from free trade whenever $t>(1-c) / 2$. If the domestic good is hardly substitutable to the foreign good, then the gain to the domestic firm from a marginal application of an anti-dumping duty in a neighborhood of free trade can be neglected. But if transport cost is high enough, the positive effect on government revenues will dominate the negative effect on the consumers' surplus. Notice that transport cost will be prohibitive if $t>(1-c) / 2$ when the goods are perfect substitutes, whereas this will occur only if $t>1-c$ when the goods are independent.

It is interesting to note that a move away from free trade can increase world welfare. To see this, suppose the two governments were to agree to jointly select $\mathrm{k}=\mathrm{K}=\alpha$ so as to maximize world welfare, which is given by $w+W$. Under those circumstances and with symmetric demands, $w+W=2 w$ and $w$ reduces to

$$
w=U(x(\alpha), y(\alpha))-c x(\alpha)-(t+c) y(\alpha) .
$$

With linear demands, one finds that

$$
\left.\underline{w}\right|_{=0}=\frac{2 a^{2} b t[2(1-c)-t]}{\left(4 a^{2}-b^{2}\right)^{2}}>0 .
$$

Therefore free trade does not maximize world welfare and governments acting cooperatively to maximize world welfare should choose to endorse the institution of anti-dumping provisions. To see why this can occur, consider the limiting case of perfect substitutes $(b=a)$. The reciprocal trade of the

16. This is the case assumed in Brander and Krugman [1983], although they do not consider the effect of anti-dumping duties. 
then perfectly identical goods causes a loss due to seemingly pointless transport costs. There is however also a gain to world welfare from the increased competition generated by this trade. ${ }^{17}$ The above result says that, with linear demands, too much reciprocal trade is occurring at free trade (i.e., at $k=K=0$ ), in the sense that the savings in transport costs from a small reduction in reciprocal trade exceeds the negative effect on welfare coming from the reduced competition.

Although the actual volume of reciprocal trade that maximizes world welfare will depend on the degree of substitutability of the goods, a similar argument carries over to the case where the goods are not perfect substitutes. In all cases, the overall effect on world welfare of the simultaneous introduction of reciprocal anti-dumping policies will be the result of a trade-off between the gain from the saving in the total transport costs and the loss from the reduced competition as a result of the reduction of intraindustry trade.

\section{Conclusion}

The possible trade-off between consumer and producer surplus has not prevented the use of anti-dumping policies from becoming a popular protectionist measure in recent years. M any reasons may be advanced for this. One possible explanation which we have raised in this paper is that in some cases the trade-off may not be very important and in fact may actually be nonexistent.

Indeed, we have shown that in a context of oligopolistic trade with differentiated products, some quite plausible conditions on demand will result in a gain from an anti-dumping duty even for the country's consumers. In such a context there is no cost and an unambiguous increase in welfare to a country of protecting its firms' profits by the use of anti-dumping duties. Furthermore, we have provided a condition, relating the degree of substitutability of the goods produced by the two countries and the transport cost, which is sufficient for recourse to anti-dumping policies by welfare maximizing governments to occur in equilibrium. As we show, this may not be detrimental

17. Brander and Krugman [1983] show that in a neighborhood of autarky, the first effect will dominate the second if transport cost is not too high and hence some reciprocal trade is better than no trade at all. 
to world welfare when trade takes place within an oligopolistic industry.

It should be pointed out finally that our analysis has relied on an assumption that dumping occurs in a context of intraindustry trade which hinges on firms pricing above marginal cost. O ur conclusions concerning the possible gains to world welfare from anti-dumping laws must therefore be interpreted in that light. As briefly noted in the introduction, there are other forms of dumping. $N$ ot all of them are harmful to welfare.

\section{Appendix}

\section{A. A Sufficient Condition for Dumping}

The purpose of this appendix is to derive sufficient restrictions on the demand functions in order for dumping to occur in free-trade equilibrium.

Suppose there is dumping of the home product into the foreign market in equilibrium, i.e., $P_{x}\left(x^{0}, y^{0}\right)+t-P_{x}\left(X^{0}, Y^{0}\right)>0$. Subtracting (4) from (3), we find that an equivalent way of writing the necessary and sufficient condition (10) is

$$
X \frac{P_{x}(X, Y)}{X}>x \frac{P_{x}(X, y)}{X} .
$$

But we know that $x^{0}>X^{0}$ and $y^{0}<Y^{0}$ when $t>0$. Hence $(A-1)$ must hold if the following does:

$$
\frac{{ }^{2} P_{x}(u, v)}{u^{2}} \leq 0 \text { and } \frac{{ }^{2} P_{x}(u, v)}{u v} \geq 0
$$

A similar reasoning applied to the foreign firm shows that imposing

$$
\frac{{ }^{2} P_{y}(u, v)}{v^{2}} \leq 0 \text { and } \frac{{ }^{2} P_{y}(u, v)}{u v} \geq 0
$$

on the demand function of the foreign firm is sufficient for dumping of the foreign product to occur.

\section{B. The Restricted Trade Equilibrium Dumping Margin}

The purpose of this appendix is to show that if $M\left(x^{0}, y^{0}, X^{0}, Y^{0}\right)>0$, so that dumping of the foreign product takes place in the free-trade equilibrium, 
then the only part of the foreign firm's reaction function which is relevant to the study of the restricted trade equilibrium is that where $M(X, y, X, Y) \geq 0$ and hence $\tau=k M(x, y, x, x)$.

To show this, suppose $M(X, y, X, Y)<0$ at the restricted trade equilibrium. Then it must be the case that in a neighborhood of this equilibrium $\tau=0$ and the profit function of the foreign firm is given by (2). This equilibrium must therefore satisfy the first-order conditions (3) to (6). But we know that $\left(x^{0}, y^{0}\right.$, $X^{0}, Y^{0}$ ) is the unique solution to conditions (3) to (6), thus contradicting the assumption that $M\left(X^{0}, y^{0}, X^{0}, Y^{0}\right)>0$.

C. The Solution to the Second Stage Equilibrium Production Levels with Linear Demands

Define

$$
\begin{array}{ll}
A(i)=a^{2} i^{2}+(1+i)\left(b^{2}-4 a^{2}\right), & i=k, k \\
B(i)=(2+i) a-(1+i) b, & i=k, k \\
C(j, i)=(j-(1+j) i) a b, & i, j=k, K, \quad i \neq j .
\end{array}
$$

Then, assuming $2 a-b>2 a t /(1-c) \geq 0$, the solution of (30) to (33) can be written

$$
\begin{aligned}
x= & \left(\frac{1}{2 a[C(K, k) C(k, K)-A(k) A(K)]}\right)\{(1-c)[C(K, k) C(k, K) \\
& -A(k) A(K)-b[B(k) A(K)-B(K) C(k, K)]+a[B(K) A(k) \\
& -B(k) C(K, K)] K]+2 \operatorname{ta}[[a(1+k) C(K, k)-(1+K) A(k)] K \\
& -b[(1+K) C(k, K)-(1+k) A(k)]]\} \\
x= & \frac{(1-C)[B(K) A(k)-B(k) C(k, K)]+2 \operatorname{ta}[(1+k) C(K, k)-(1+K) A(k)]}{C(K, k) C(k, K)-A(k) A(K)} \\
y= & \frac{(1-C)[B(K) A(K)-B(K) C(K, k)]+2 \operatorname{ta}[(1+K) C(K, K)-(1+k) A(K)]}{C(K, K) C(k, K)-A(k) A(K)}
\end{aligned}
$$




$$
\begin{aligned}
Y= & \left(\frac{1}{2 a[C(K, k) C(k, K)-A(k) A(K)]}\right)\{(1-c)[C(k, K) C(K, k) \\
& -A(K) A(k)-b[B(K) A(k)-B(k) C(k, K)]+a[B(k) A(K) \\
& -B(K) C(k, K)] k]+2 \operatorname{ta}[[a(1+K) C(k, K)-(1+k) A(K)] k \\
& -b(1+k) C(K, k)-(1+K) A(K)]]\} .
\end{aligned}
$$

\section{References}

Anderson, J. E. [1992], “D omino Dumping, I: Competitive Exporters," Amer ican E conomic Review, Vol. 82; pp. 65-83.

Anderson, J. E. [1993], "Domino Dumping, II: Anti-dumping," Journal of International Economics, Vol. 35; pp. 133-150.

Anderson, S., Schmitt, N. and Thisse, J. F. [1995], "Who Benefits From Antidumping Legislation?," Journal of I nternational E conomics, Vol. 38; pp. 321-337.

Brander, J. and Krugman, P. [1983], "A 'Reciprocal Dumping' Model of International Trade," Journal of International Economics, Vol. 15; pp. 313-321.

Davies, S. and McGuinness, A. [1982], "Dumping at Less than M arginal Cost," Journal of International Economics, Vol. 12; pp. 169-182.

Deardorff, A. V. [1989], "E conomic Perspectives on Antidumping Law," in Antidumping Law and Practice: A Comparative Study, ed. J. H. Jackson and E. A Vermulst. Ann Arbor, M ichigan: The University of M ichigan Press; pp. 23-39.

Dixit, A. [1988], "Anti-dumping and Countervailing Duties under Oligopoly," European Economic Review, Vol. 32; pp. 55-68.

Eaton, J. and L. J. M irman [1991], "Predatory Dumping as Signal J amming," in Trade Policy and International Adjustment, ed. A. Takayama, M. Ohyama and H Ohta. New York: Academic Press; pp.60-76.

Ethier, W. [1982], "Dumping," Journal of Political Economy, Vol. 90; pp. 487506.

Fudenberg, D. and J. Tirole [1986], "A 'Signal J amming' Theory of Predation," Rand Journal of E conomics, Vol. 17; pp.366-376. 
Hartigan, J. C. [1994], "Dumping and Signaling," Journal of Economic Behavior and Organization, Vol. 23; pp. 69-81.

Hartigan, J. C. [1995], "Collusive Aspects of Cost Revelation through Antidumping Complaints," Journal of Institutional and Theoretical Eco nomics, Vol. 151; pp.478-489.

Hartigan, J. C. [1996], "Predatory Dumping," Canadian Journal of E conom ics, Vol. 29; pp. 228-239.

Jackson, J. H. [1989], "D umping in International Trade: Its M eaning and Context," in Antidumping Law and Practice: A Comparative Study, ed. J. H. Jackson and E. A. Vermulst. Ann Arbor, M ichigan: The University of M ichigan Press; pp. 1-22.

M oore, M. O. and S. M. Suranovic [1994], "Welfare E ffects of Introducing Antidumping Procedures in a Trade-Liberalizing Country," Journal of Economic Integration, Vol. 9; pp. 241-259.

Pinto, B. R. [1986], "Repeated Games and the 'Reciprocal Dumping' M odel of Trade," Journal of International Economics, Vol. 20; pp. 357-366.

Prusa, T. J. [1992], "Why Are So M any Antidumping Petitions Withdrawn," Journal of International Economics, Vol. 33; pp.1-20.

Prusa, T. J. [1994], "Pricing Behavior in the Presence of Antidumping Law," Journal of Economic Integration, Vol. 9; pp. 260-289.

Reitzes, J. D. [1993], "Antidumping Policy," International Economic Review, Vol. 34; pp.745-763.

Staiger, R. W . and F. A. W olak [ 1992], "The Effect of Domestic Antidumping Law in the Presence of Foreign Monopoly," Journal of International Economics, Vol. 32; pp. 265-287.

Webb, M . [1992], "The Ambiguous Consequences of Anti-D umping Laws," E conomic Inquiry, Vol. 30; pp. 437-448.

Weinstein, D. [1992], "Competition and Unilateral Dumping," Journal of International Economics, Vol. 32; pp. 379-388. 